\title{
1 Lateral and longitudinal fish eDNA distribution in 2 dynamic riverine habitats
}

3

4 Running title: spatio-temporal eDNA distribution

5

6

7

$$
8
$$

9 Guelph, Ontario, Canada Technology, Dübendorf, Switzerland Mondsee, Austria

${ }^{6}$ Sinsoma $\mathrm{GmbH}$, Lannes 6, 6176 Voels, Austria

*Corresponding author:

Bettina Thalinger, bettina.thalinger@gmail.com

Bettina Thalinger ${ }^{1,2^{*}}$, Dominik Kirschner ${ }^{1,3}$, Yannick Pütz ${ }^{1}$, Christian Moritz ${ }^{4}$, Richard Schwarzenberger $^{4}$, Josef Wanzenböck ${ }^{5}$ \& Michael Traugott ${ }^{1,6}$

${ }^{1}$ Department of Zoology, Universität Innsbruck, Technikerstr. 25, 6020 Innsbruck, Austria

${ }^{2}$ Centre for Biodiversity Genomics, University of Guelph, 50 Stone Road E, N1G2W1,

${ }^{3}$ Department of Aquatic Ecology, Eawag: Swiss Federal Institute of Aquatic Science and

${ }^{4}$ ARGE Limnologie GesmbH, Hunoldstr. 14, 6020 Innsbruck, Austria

${ }^{5}$ Research Department for Limnology, Mondsee, Universität Innsbruck, Mondseestr. 9, 5310

Centre for Biodiversity Genomics, University of Guelph, 50 Stone Road E, N1G 2W1, Guelph, Ontario, Canada; phone: +1 519-824-4120 Ext. 53800

Keywords: lotic, environmental DNA, hydrology, sampling scheme, eDNA plume 


\section{Abstract}

34 Assessing the status and distribution of fish populations in rivers is essential for management and conservation efforts in these dynamic habitats. Currently, methods detecting environmental DNA (eDNA) are being established as an alternative and/or complementary approach to the traditional monitoring of fish species. In lotic systems, a sound understanding of hydrological conditions and their influence on the local target detection probability and DNA quantity is key for the interpretation of eDNA-based results. However, the effect of seasonal and diurnal changes in discharge and the comparability of semiquantitative results between species remain hardly addressed. We conducted a cage experiment with four fish species (three salmonid and one cyprinid species) in a glacier-fed, fish-free river in Tyrol (Austria) during summer, fall, and winter discharge situations (i.e. 25fold increase from winter to summer). Each season, water samples were obtained on three consecutive days at 13 locations downstream of the cages including lateral sampling every 1-2 $m$ across the wetted width. Fish eDNA was quantified by species-specific endpoint PCR followed by capillary electrophoresis. Close to the cages, lateral eDNA distribution was heterogenous and mirrored cage placement within the stream. In addition to the diluting effect of increased discharge, longitudinal signal changes within the first $20 \mathrm{~m}$ were weakest at high discharge. For downstream locations with laterally homogenous eDNA distribution, the signals decreased significantly with increasing distance and discharge. Generally, the eDNA of the larger-bodied salmonid species was less frequently detected, and signal strengths were lower compared to the cyprinid species. This study exemplifies the

54 importance of hydrological conditions for the interpretation of eDNA-based data across seasons. To control for heterogenous eDNA distribution and enable comparisons over time, sampling schemes in lotic habitats need to incorporate hydrological conditions and species

57 traits.

58

59 Keywords: lotic, environmental DNA, hydrology, sampling scheme, Salmo trutta,

60 Oncorhynchus mykiss, Salvelinus fontinalis, Phoxinus phoxinus, 
61

62

63

64

65

66

67

68

69

70

71

72

73

74

75

76

77

78

79

80

81

82

83

84

85

86

87

88

\section{Introduction}

In times of rapid environmental changes there is a growing need for biomonitoring in both terrestrial and aquatic systems (Cardinale et al., 2012; Tickner et al., 2020). Reliable and cost-effective approaches for species detection are thus key for tracking species in time and space and informing conservation and management efforts (Jetz et al., 2019). Molecular methods, like the detection of environmental DNA (eDNA) released by organisms into their environment, have the capacity to accommodate this demand as they are non-invasive, sensitive, and enable the processing of large sample numbers (Barnes \& Turner, 2016; Deiner et al., 2017; Thomsen \& Willerslev, 2015). In aquatic habitats, eDNA can be used for the monitoring of taxa in both lotic and lentic systems with a focus on endangered or invasive species and flexible year-round application (Beng \& Corlett, 2020; e.g. Harper, Griffiths, et al., 2019; Thomsen \& Willerslev, 2015).

Rivers and streams contain, absorb, and transport eDNA from aquatic and terrestrial species and are thus ideal for cross-habitat species detection (Deiner, Fronhofer, Mächler, Walser, \& Altermatt, 2016; Sales et al., 2020), although the dynamic nature of these ecosystems leads to constantly changing conditions during sampling (Shogren et al., 2017; Willett, McCoy, Taylor Perron, Goren, \& Chen, 2014). Nevertheless, aspects such as a species' upstream distribution limits (Carim et al., 2019; Robinson, de Leaniz, \& Consuegra, 2019) or local abundance and its change over time (Doi et al., 2017; Levi et al., 2019; Thalinger, Wolf, Traugott, \& Wanzenböck, 2019) have been successfully examined in lotic systems via eDNA. Often, these efforts are combined with traditional monitoring techniques to confirm molecular results and facilitate their interpretation (Evans, Shirey, Wieringa, Mahon, \& Lamberti, 2017; Wilcox et al., 2016) and there is generally a good consensus between molecular and non-molecular data.

However, changes in hydrological conditions have profound influence on the distribution and persistence of eDNA in the water column (reviewed by Harrison, Sunday, \& Rogers, 2019), which makes the interpretation of local eDNA signals or comparisons between sampling campaigns challenging. The longitudinal eDNA detection probability in 
89

90

91

92

93

94

95

96

97

98

rivers depends on dilution, transport, deposition, resuspension, and degradation (reviewed by Harrison et al., 2019). These effects were examined for small streams (Fremier, Strickler, Parzych, Powers, \& Goldberg, 2019; Shogren et al., 2017; Wilcox et al., 2016) and large river systems (Deiner \& Altermatt, 2014; Pont et al., 2018), revealing the behavior of eDNA as similar to that of fine particulate organic matter. Recently, studies also focused on lateral eDNA distribution, describing a "plume" downstream of the source and gradual lateral homogenization with increasing downstream distance (Laporte et al., 2020; Wood, Erdman, York, Trial, \& Kinnison, 2020). Albeit discharge-associated changes in longitudinal eDNA distribution were previously examined for small streams (Jane et al., 2015), changes in the size and shape of eDNA plumes have been neglected so far.

Alpine rivers exemplify the benefits of eDNA-based monitoring as well as the challenges associated with sampling campaigns in such dynamic ecosystems. The prevailing low water temperatures permit only humble population densities and a limited species inventory at risk of biodiversity loss due to increased climate change effects (Settele et al., 2015). Anthropogenic influences in the form of straightened riverbeds, hydropower plants and dams add to this strained situation and intensify the need for monitoring the remaining natural fish populations (Faulks, Gilligan, \& Beheregaray, 2011; Fette, Weber, Peter, \& Wehrli, 2007). The discharge in these rivers varies with changing seasons from winter drought to high water levels in spring and summer (snow melt and glacial melt), with intermediate conditions in fall. Additionally, the melting processes induce substantial diurnal discharge changes in spring and summer (Bard et al., 2015). Therefore, traditional monitoring via electrofishing is only possible outside of protected periods (e.g. spawning seasons) and at low discharge and turbidity in fall and early winter. eDNA-based approaches can potentially overcome these limitations, but only after accounting for the spatio-temporal dynamics of Alpine rivers and by optimizing sampling schemes and carefully interpreting the obtained results.

In this study, we examined changes in lateral and longitudinal eDNA distribution between seasons in a glacier-fed Alpine river. The experiments were conducted with caged 
117 fish and we used species-specific endpoint PCR combined with capillary electrophoresis

118 (celPCR) to investigate how lateral and longitudinal eDNA detection probability and signal

119 strength vary on a small scale $(\leq 20 \mathrm{~m})$ between summer, fall, and winter, (i.e. high, medium, 120 and low water levels) with up to 25 -fold variations in discharge. Additionally, the longitudinal 121 change in eDNA signal strength was examined at an intermediate scale $(\sim 1 \mathrm{~km})$ for fish 122 species of different size, but constant total biomass.

Materials and Methods

Study site

127 The three caged-fish trials took place in the Melach, a fish-free, glacier-fed, Alpine river in

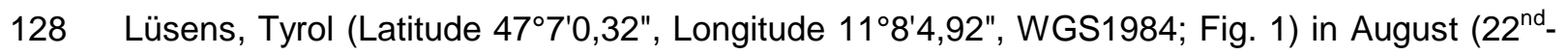
$\left.26^{\text {th }}\right) 2016$, November $\left(21^{\text {st }}-25^{\text {th }}\right) 2016$, and September $\left(26^{\text {th }}-29^{\text {th }}\right)$ 2017. The Melach shows seasonal and daily fluctuations in discharge and sediment load, typical for glacially influenced rivers in the Alps (Sertić Perić, Jolidon, Uehlinger, \& Robinson, 2015). Following the European river zonation, the sampling site is located in the epirhithral of the river at an elevation of $1700 \mathrm{~m}$ a.s.I. Permanent fish populations cannot be established in this part of the river due to extreme discharge situations. Additionally, a transverse structure at the downstream end of the examined range prohibited potential upstream migration.

Experimental design

138 All handling of study animals conformed to Directive 2010/63/EU, and permission for field 139 work was granted by the fishing area manager $\mathrm{H}$. Raffl. Prior to the experiment, the absence 140 of fish was confirmed via electrofishing, starting $1.3 \mathrm{~km}$ downstream at the transverse 141 structure. For each of the three trials, two steel cages $1 \times 1 \times 0.6 \mathrm{~m}$ with "mesh" size of $14210 \mathrm{~mm}$ and $5 \mathrm{~mm}$, respectively, were installed at the same location in full current of the river 143 for the duration of the experimental run (four days), secured against drift, and equipped with 144 a few stones to provide natural structure and potential resting places. Four fish species were 
145 used in the experiment: a cyprinid species (Eurasian minnow - Phoxinus phoxinus L. 1758)

146 was placed in the cage with the narrow mesh size and three salmonid species (brown trout -

147 Salmo trutta L. 1758, brook trout - Salvelinus fontinalis M. 1814, and rainbow trout -

148 Oncorhynchus mykiss W. 1792) were placed in the other cage. On days two, three, and four

149 of each trial, a minimum of $200 \mathrm{~g}$ fish per species (exception: $P$. phoxinus on day one in

150 August (196 g) and in November (183 g)) were placed in the cages, corresponding to two to

151 five individuals per salmonid species and 40 to $90 P$. phoxinus individuals. At the end of each

152 sampling day, fish were removed from the cages and exchanged for new individuals to

153 generate true biological replicates, prevent acclimation to the local conditions, and reduce

154 stress-periods for the animals. The fish were kept in separate tanks afterwards to avoid the

155 multiple use of individuals. Due to their life cycle and therefore a lack of catchable

156 individuals, the availability of $P$. phoxinus was limited in November and the same individuals

157 had to be used on all sampling days.

158 Two-liter water samples were used for the detection of fish eDNA. On the first day of 159 each trial (prior to fish placement in cages), control samples were taken from at least five 160 locations between the cage position and the transverse structure. On days two, three, and 161 four, water samples were taken daily at 13 locations downstream of the cages $(1.3 \mathrm{~km}$, 162555 m, 425 m, 325 m, 225 m, 130 m, 65 m, 33 m, 17 m, 8 m, 4 m, 2.5 m, and 0.5 m; Fig. 1) 163 at approximately the same daytime and before fish were exchanged. Because of changes in 164 the structure of the riverbed, the distance between the cages and the first seven transects 165 sometimes varied by one to two meters between trials, which was accounted for during data 166 analyses. At $0.5 \mathrm{~m}$ to $130 \mathrm{~m}$ distance, two to four water samples were taken in lateral 167 transects, depending on the width of the river (Fig. 1). Further downstream, we took one 168 sample per location. In November, only two to three lateral transect samples were taken due 169 to limited discharge, resulting in reduced wetted width and sampling at transect 5 had to be 170 omitted due to a slight position change of the cages. Each day, sampling was carried out 171 from the most downstream location moving upstream towards the cages. In September, two 172 sampling runs from $1.3 \mathrm{~km}$ to $0.5 \mathrm{~m}$ downstream distance were carried out per day. 
174 bottles, which had been treated with chlorine bleach (3.6 g sodium hypochlorite per $100 \mathrm{~g}$ 175 liquid) overnight and thoroughly washed using fish-DNA-free tap water. Filtration was carried 176 out on $500 \mathrm{ml}$ filter towers with a peristaltic pump (Solinst; Model 410) and glass fibre filters 177 with $47 \mathrm{~mm}$ diameter $\left(1.2 \mu \mathrm{m}\right.$ mesh width, Whatman GF/C), followed by storage at $-80^{\circ} \mathrm{C}$ 178 until further processing. In case of filter clogging (high turbidity; only in August), up to three 179 filters were utilized per sample. During all water processing steps, DNA-free gloves were worn and frequently changed. All multi-use equipment was soaked in chlorine bleach for at least ten minutes between samples and thoroughly rinsed using MilliQ water. Forceps for filter handling were singed three times prior to each use. Every ten samples, $2 \mathrm{~L}$ of MilliQ water were filtered as negative controls to check for cross-contamination during fieldwork, whereas a sample from the fish transport container served as daily positive control.

Total discharge and its lateral differences were measured with a FlowTracker 186 (Sontek, USA) during the August trial, and with salt and a TQ Tracer (Sommer Messtechnik, 187 Austria) during the November and September trials. In August, discharge increased during 188 the sampling time (10 AM to $5 \mathrm{PM}$ ) due to the strong glacial influence but remained constant 189 along the sampling reach. Therefore, diurnal discharge was measured once and supported 190 by point-measurements at 3 PM. In September and November, the inflow of tributaries caused an increase along the $1.3 \mathrm{~km}$ sampling reach, with hardly any changes in the course of a day. Hence, measurements were carried out daily directly at the cages, at $225 \mathrm{~m}, 555 \mathrm{~m}$, and $1.3 \mathrm{~km}$ downstream, and supported by a diurnal measurement per trial. Discharge at

194 each water sampling point (in space and time) was interpolated; no rainfall occurred during 195 any of the sampling days. For all three trials, turbidity was measured with a turbidity meter using an infrared light source (AL250T-IR, Aqualytic, Germany). Water temperature, $\mathrm{pH}$, conductivity, and oxygen saturation were obtained with a multi-parameter probe (WTW,

198 Germany). 
201 All molecular work was carried out in a clean-room laboratory at the University of Innsbruck

202 (Austria) compliant with ancient-DNA processing standards. First, filters were lysed using $203190 \mu \mathrm{L}$ TES (0.1 M TRIS, 10mM EDTA, 2\% sodium dodecyl sulphate; pH 8) and $10 \mu \mathrm{L}$ 204 Proteinase $\mathrm{K}(\mathrm{VWR}, 20 \mathrm{mg} / \mathrm{mL}$ ) each, followed by over-night incubation on a rocking platform at $56^{\circ} \mathrm{C}$. Then, filters were transferred to plastic inserts with a perforated bottom and centrifuged for $10 \mathrm{~min}$ at $14,000 \mathrm{rpm}$. The entire resulting lysate was extracted on the Biosprint 96 platform (QIAGEN) using a custom DNA-uptake protocol which combined the DNA contained in up to $900 \mu \mathrm{L}$ lysate prior to extraction with the "BS 96 tissue protocol" according to the manufacturer's instructions; except for elution in $100 \mu \mathrm{L}$ TE. Lysates of

210 filters stemming from the same water sample were combined during the uptake process.

211 Each 96-well plate contained four extraction negative controls and all resulting eluates were 212 stored at $-32^{\circ} \mathrm{C}$ until further processing.

213 Target DNA was amplified using species-specific primers and celPCR. These were 214 run on Nexus Mastercyclers (Eppendorf); each plate included at least one positive control 215 (DNA extract from target species) and one negative control (molecular grade water). 216 Previously published primers (Thalinger et al., 2016) and a newly developed primer pair for 217 S. trutta (Table 1) were utilized. During PCR optimization, primers were tested for specificity 218 against other fish species and aquatic invertebrates occurring in Central European 219 freshwaters (Thalinger et al., 2016). Additionally, we specified assay sensitivity following Sint et al. (2012): reliable positive amplifications were possible for all primer pairs from 10 DNA ds. Each $10 \mu \mathrm{L}$ PCR master mix contained $1 \times$ Multiplex reaction mix (QIAGEN), $0.5 \mu \mathrm{M}$ of each primer, $30 \mathrm{mM}$ TMAC, $5 \mu \mathrm{g}$ BSA (Bovine Serum Albumin) and $3.2 \mu \mathrm{L}$ DNA extract. Optimized thermocycling conditions were: denaturation at $95^{\circ} \mathrm{C}$ for $15 \mathrm{~min}, 35$ cycles of $94^{\circ} \mathrm{C}$ for $30 \mathrm{~s}, 64^{\circ} \mathrm{C}\left(66^{\circ} \mathrm{C}\right.$ for $P$. phoxinus $)$ for $3 \mathrm{~min}$ and $72^{\circ} \mathrm{C}$ for $60 \mathrm{~s}$ followed by final elongation at $72^{\circ} \mathrm{C}$ for $10 \mathrm{~min}$. Target DNA signal strength was determined via capillary electrophoresis on the QIAxcel (QIAGEN) with the associated software QIAxcel Screengel version 1.6.0.10 using the method AM320-30s. The fluorescent signal measured in Relative Fluorescence Units (RFU) was used as a semi-quantitative measure of target DNA (Thalinger, Pütz, \& 
229 Traugott, 2020; Thalinger et al., 2019) and signals $\geq 0.08$ RFU were deemed positive. To 230 verify the applicability of this approach, 40 samples positive for $S$. trutta were re-tested with 231 digital PCR (Supporting Information (SI) 1a). All extraction and PCR negative controls 232 resulted negative, however, in the August and the November trial six of 16 negative controls 233 showed low levels of contamination ( $\leq 0.2 \mathrm{RFU})$, hence, fluorescence values of potentially 234 affected field samples (10.9\% of all obtained PCR results) were down-corrected by the 235 respective values.

236

237 Statistical analysis

238 All data were analyzed in R (R Core Team, 2020) and visualized with "ggplot2" (Wickham, 239 2016), "ggpubr" (Kassambara, 2019), and "viridis" (Garnier, 2018). We generated species240 specific eDNA heatmaps for each trial until $65 \mathrm{~m}$ downstream distance and subsequently 241 heatmaps per fish cage, i.e. for salmonids and P. phoxinus, for each of the three trials up to $24220 \mathrm{~m}$. The lateral distance from the orographically left shore $(\mathrm{x})$, the longitudinal distance 243 from the respective cage $(y)$ and mean RFU (z) were used for the linear interpolation of 244 irregular gridded data with the "akima" package (Akima \& Gebhardt, 2016). eDNA signals 245 were not extrapolated towards the edge of the water body and RFU were interpolated on a 246 $5 \times 5 \mathrm{~cm}$ grid.

247 Differences in detection rates and eDNA signal strengths amongst salmonid species 248 up to $33 \mathrm{~m}$ downstream distance were examined per trial with Z-tests, Kruskal-Wallis tests, 249 and Holm-Sidak-corrected p-values. As no significant differences were detected (SI 1b), 250 salmonid data remained pooled for the subsequent analysis of small-scale lateral and 251 longitudinal eDNA distribution using the packages "reshape2" (Wickham, 2007), "ade4" 252 (Bougeard \& Dray, 2018; Chessel, Dufour, \& Thioulouse, 2004), and "data.table" (Dowle \& 253 Srinivasan, 2020). Lateral changes in interpolated eDNA signals were examined per cage 254 and trial at $2.5 \mathrm{~m}, 5 \mathrm{~m}, 10 \mathrm{~m}$ and $20 \mathrm{~m}$ by testing salmonid and P. Phoxinus data for 255 normality and calculating their Spearman Rank Correlation and Holm-Sidak-corrected p256 values. To investigate the magnitude of longitudinal eDNA signal changes between $2.5 \mathrm{~m}$ 
257 and $20 \mathrm{~m}$, differences between eDNA signals of adjacent interpolated datapoints were 258 calculated $1 \mathrm{~m}$ from the left shore, at the stream center, and $1 \mathrm{~m}$ from the right shore 259 individually for each trial, and salmonids and P. phoxinus, respectively. Differences were 260 tested for normality and per position, Kruskal-Wallis tests followed by pairwise Wilcoxon261 Rank-Sum tests were used to compare between trials for each position (left, center, right) 262 and fish cage (salmonids, P. phoxinus); all p-values were Holm-Sidak-corrected.

263 To analyze the relationship between eDNA signals, distance from the cages, and 264 discharge on a larger scale, only lateral transects with homogenous eDNA distribution at all 265 trials were considered. Therefore, salmonid RFU were tested for normal distribution with a 266 Shapiro-Wilk test, followed by Kruskal-Wallis tests per transect and trial. P. phoxinus data 267 were not considered as the dataset was too small for separate testing and mirrored lateral 268 eDNA distributions between the two cages would potentially mask patterns, if considered 269 together. Based on these tests (SI 1c), only data with downstream distances $\geq 130 \mathrm{~m}$ were used for the two subsequent analyses: once entering detections as binary variable $(0 / 1)$, and 271 once using RFU of positive samples and considering non-detections as random results 272 induced by the sampling process (Hagenaars \& McCutcheon, 2002). To account for the 273 binary nature and the right-skewed distribution of RFU, Generalized Linear Models (GLM) 274 were used with family "binomial" and a logit-link for detections (0/1) and family "Gamma" with 275 a log-link for RFU (Faraway, 2016). After initial data inspection, discharge, downstream 276 distance, their interaction and fish species were entered as independent variables in both 277 models, and P. phoxinus was set as base category (see SI 2 for the complete R code). For 278 both models, simulated, scaled residuals were calculated (package: "DHARMa" (Hartig, 279 2020); function: "simulateResiduals"; $n=1,000)$ to confirm model fit and test for outliers and 280 overdispersion.

281

282

\section{Results}


284 Altogether, 306 water samples were analyzed: 84, 168, and 54 from the August, September, 285 and November trial, respectively, and average discharge during sampling 0-20 m downstream of the cages was $835 \mathrm{~L} / \mathrm{s}$ in August, $174 \mathrm{~L} / \mathrm{s}$ in September, and $61 \mathrm{~L} / \mathrm{s}$ in November (maximum 1,593 L/s in August; minimum 59,3 L/s in November). Fifty percent of the 1,224 PCRs resulted positive with the majority of detections occurring in September and November. The environmental variables turbidity $(0-4.6$ NTU), oxygen saturation $(9.43-$ $11.25 \mathrm{mg} / \mathrm{L})$, water temperature, $\left(4.2-10.5^{\circ} \mathrm{C}\right)$, conductivity $(49.3-69.2 \mu \mathrm{S} / \mathrm{cm})$, and $\mathrm{pH}$ (7.11 - 7.6) were near-constant between the three trials. Only in August during sampling within $100 \mathrm{~m}$ of the cages (i.e. at a later daytime) turbidity increased (88.7 NTU \pm 50.3 NTU SD) and conductivity decreased $(36.5 \mu \mathrm{S} / \mathrm{cm} \pm 9.70 \mu \mathrm{S} / \mathrm{cm}$ SD) because of glacial run-off. Within the first $33 \mathrm{~m}$ downstream of the cages, RFU per trial did not differ between the three salmonid species $(1<\mathrm{p}>0.11$; SI $1 \mathrm{~b})$, leading to a combined analysis of salmonid eDNA signals on a small scale: heatmaps of eDNA signals up to $20 \mathrm{~m}$ downstream of the cages revealed eDNA plumes below the respective fish cage and much weaker or no signals at small lateral distances of $\sim 1 \mathrm{~m}$ (Fig. 2; see SI 3 for species-specific heatmaps until $65 \mathrm{~m}$ downstream distance). In August, cages were placed in the center of the stream and positive samples within $20 \mathrm{~m}$ distance were almost exclusively obtained from sampling points with no lateral offset (Fig. 1 and Fig. 2). The interpolated eDNA signals of the salmonids and P. phoxinus obtained in August showed significant positive correlations at all examined distances $(2.5 \mathrm{~m}, 5 \mathrm{~m}, 10 \mathrm{~m}$, and $20 \mathrm{~m} ; \mathrm{p}<0.001$; Table 2). In September, the main water flow out of the salmonid cage was observed towards the orographically right edge of the river; the main water flow from the $P$. phoxinus cage was on the opposite side. This situation was mirrored by high target eDNA signals downstream of the respective cage, low eDNA signals at the opposite sides, and significantly negative correlations between salmonid and P. phoxinus RFU at $2.5 \mathrm{~m}(\mathrm{p}<0.001), 5 \mathrm{~m}(\mathrm{p}<0.05)$ and $10 \mathrm{~m}(\mathrm{p}<0.001$; Table 2). In

309 November, eDNA signals were highest for both salmonids and $P$. phoxinus and the eDNA 310 distribution pattern was back-to-front in comparison to September: the main water flow was 311 observed on the orographically left side below the salmonid cage and the orographically right 
312 side below the $P$. phoxinus cage leading to significant negative correlations at $5 \mathrm{~m}$

$313(p<0.001)$ and $10 \mathrm{~m}(p<0.001$; Table 2$)$. The small-scale longitudinal changes of the 314 interpolated eDNA signals at the left, center, and right position differed significantly between 315 trials for both salmonids and P. phoxinus; exceptions were salmonid signals from the right 316 position and P.phoxinus signals from the left position, which did not differ significantly 317 between August and September, respectively (Table 3). The longitudinal changes were 318 strongest in November, with e.g. P. phoxinus values decreasing on average $0.036 \mathrm{RFU} \pm$ 3190.05 RFU SD with each meter; the smallest changes were detected for salmonids in August 320 at the left and right position (Table 3, Fig. 2).

321

At $130 \mathrm{~m}$ downstream distance from the cages and beyond, salmonid signals were 322 laterally homogenous during all three trials $(\mathrm{SI} 1 \mathrm{c})$ and thus used to examine large-scale 323 patterns of detection rates and RFU. In August, only few samples resulted positive with low 324 mean values (e.g. P. phoxinus 0.25 RFU \pm 0.16 RFU SD; Fig. 3 and Fig. 4). In September, 325 the signals remained at a similar level, but $100 \%$ of $P$. phoxinus PCRs and $71 \%$ of salmonid species PCRs resulted positive. In November, mean $P$. phoxinus eDNA signals were highest (0.34 RFU \pm 0.22 RFU SD), and salmonid signals remained similar to September (Fig. 3 and Fig. 4). The longitudinal increase in discharge was similar in September and November with a 2.1 -fold increase from $201 \mathrm{~L} / \mathrm{s}$ to $335 \mathrm{~L} / \mathrm{s}$ and a 2.7 -fold increase from $71 \mathrm{~L} / \mathrm{s}$ to $167 \mathrm{~L} / \mathrm{s}$, 330 respectively (Fig. 3). Both GLMs (for binomial data and RFU) passed the diagnostics for model fit, outliers, and overdispersion. They displayed similar patterns of parameter estimates and significances (Table 4 and Table 5): salmonids were significantly less likely to be detected and had significantly lower RFU in comparison to P. phoxinus. Discharge and downstream distance were significantly correlated in both models and only the individual effect of discharge was not significant ( $p>0.05)$ in the Gamma GLM (Table 5).

336

337

\section{Discussion}


339 Our results demonstrate profound spatio-temporal changes in eDNA distribution induced by

340 seasonal discharge conditions. Until $20 \mathrm{~m}$ the lateral position of the eDNA plumes

341 downstream of the caged fish mirrored their position inside the river with salmonid and

342 P. phoxinus plumes in the stream center in August and on opposing sides in September and

343 November. Small-scale longitudinal changes in eDNA signals were strongest at low

344 discharge in November, and lateral mixing occurred further downstream at higher discharge

345 in August when significant lateral differences were detected at $65 \mathrm{~m}$. Additionally, the small-

346 sized $P$. phoxinus individuals emitted a significantly stronger eDNA signal and had higher

347 detection rates than the three larger-bodied salmonid species, principally in November. Along

348 the $1.3 \mathrm{~km}$ flow path, increasing discharge and distance both had significantly negative

349 effects on detection rates and eDNA signal strength.

350 The eDNA signals recorded at a small lateral and longitudinal scale $(\leq 20 \mathrm{~m})$ coincide

351 with previous results describing a plume-shaped distribution of eDNA downstream of the 352 source (Laporte et al., 2020; Wilcox, McKelvey, Young, Lowe, \& Schwartz, 2015; Wood et

353 al., 2020). Additionally, the shape of the salmonid and P. phoxinus plume (averaged across

354 three sampling days) mirrored the lateral position of the respective cage when these were

355 not aligned in flow direction in September and November. This finding complicates the

356 interpretation of field-derived eDNA results when local conditions differ across the wetted

357 width, especially as individual species may prefer specific micro-habitats depending on

358 hydrological conditions (e.g. seek shelter from high flow velocities) (Aarts \& Nienhuis, 2003).

359 Based on our experimental setup with constant fish biomasses, it was not possible to confirm

360 the results of Wood et al. (2020) who found a positive correlation between eDNA quantities

361 and detection probability at higher lateral distance. However, our data show a comparable

362 effect induced by lower discharge and slower flow velocities (Wondzell, Gooseff, \& McGlynn,

363 2007) at constant fish biomass. Future studies examining lateral and longitudinal eDNA

364 distribution should therefore take biomass-induced variations and hydrological effects into

365 account. 
All three salmonid species (average individual mass $101 \mathrm{~g}$ ) had lower detection

367 probabilities and lower eDNA signals than $P$. phoxinus (average individual mass $3.5 \mathrm{~g}$ ) at similar total biomass, a finding which was primarily driven by the results of the trial in November. eDNA shedding rates and biomass in most cases exhibit a positive relationship in

370 controlled and natural settings (Lacoursière-Roussel, Rosabal, \& Bernatchez, 2016;

371 Takahara, Minamoto, Yamanaka, Doi, \& Kawabata, 2012; Thalinger et al., 2019). Maruyama

372 et al. (2014) detected elevated levels of eDNA release per gram bodyweight in juvenile fish

373 and recently, allometrically scaled fish mass was found to best describe the relationship 374 between eDNA signals and brook trout populations in lakes (Yates et al., 2020). In the 375 present study, several scenarios can explain the difference in detection probability and signal 376 strength: the P. phoxinus individuals, although mostly not juvenile, could indeed have had 377 higher metabolic rates (Vinberg, 1960), which are common for smaller fish species (Clarke \& 378 Johnston, 1999). The increased surface to volume ratio of the smaller fish is another 379 potential explanation as more $P$. phoxinus surface was exposed to the water flow. The eDNA 380 release rates could generally differ between cyprinids and salmonids, which also exhibit 381 structural and physiological differences (Freyhof \& Kottelat, 2007). Albeit the daily exchange 382 of fish individuals after eDNA sampling was another potential source of variation (e.g. slight 383 changes in total biomass or individual counts) we deemed this measure appropriate to obtain 384 true biological replicates, avoid acclimation effects to the stream environment, and minimize 385 the exposure to stressful flow conditions. Generally, the salmonids were better adapted to 386 the high flow conditions in August, when some P. phoxinus did not survive the exposure to $3871,500 \mathrm{~L} / \mathrm{s}$ discharge. This could explain the distinct detection probability for $P$. phoxinus, as 388 dead individuals can emit more eDNA into the water (Tillotson et al., 2018). However, the 389 difference in eDNA signal strength was principally found in November at $\sim 60 \mathrm{~L} / \mathrm{s}$, when all 390 but one individual of $P$. phoxinus survived. Though celPCR assay optimization (Sint et al., 391 2012; Thalinger et al., 2016) can not fully account for differences in amplification efficiency 392 between primer pairs (Thalinger et al., 2020), primer bias is an unlikely cause for the strong 393 P. phoxinus signals, because detection patterns and signal strength did not differ between 
394 the salmonids. Nevertheless, celPCR produces a semi-quantitative measure of target copy 395 numbers and without direct comparison to a fully quantitative approach (i.e. digital PCR), it is 396 not possible to infer absolute eDNA concentrations from RFU (Thalinger et al., 2020). Most 397 likely, the strong eDNA signals of $P$. phoxinus can be attributed to a combination of the 398 aforementioned physiological and morphological differences. These effects could be even 399 stronger when fish are compared to other aquatic groups such as amphibians, mussels, or 400 crayfish (Bedwell \& Goldberg, 2020; Robinson, Uren Webster, Cable, James, \& Consuegra, 401 2018; Wacker et al., 2019).

402 As expected for glacier-fed Alpine rivers and streams, discharge changed 403 substantially (25-fold) between trials (Bard et al., 2015). The associated diluting effect was 404 clearly visible from eDNA signal strengths directly downstream of the cages $(\leq 20 \mathrm{~m})$ : average $405 P$. phoxinus signals at this location ranged from $0.30 \mathrm{RFU} \pm 0.30 \mathrm{RFU}$ SD in August to 406 1.06 RFU $\pm 0.46 \mathrm{RFU} \mathrm{SD}$ in November. Few of the samples taken at high discharge $407>1,000 \mathrm{~L} / \mathrm{s}$ in August tested positive, but in this situation the $200 \mathrm{~g}$ fish mass per species 408 were less than $0.2 \%$ of the passing water mass. The summer situation was most 409 challenging to examine, as discharge and turbidity increased from morning $(\sim 270 \mathrm{~L} / \mathrm{s}$ and 410 clear water) to afternoon ( 1,100 L/s and high turbidity). The analysis of samples with high 411 variations in turbidity should include this variable in the modelling process to account for 412 changes in extraction efficiency and inhibition associated with increased turbidity (Harper, 413 Buxton, et al., 2019). We refrained from doing so as the samples taken in August at high 414 turbidity were not part of the dataset used for modelling. In contrast to classic fish monitoring 415 via electrofishing, eDNA-based methods are not restricted to low flow conditions outside of 416 protected periods and spawning seasons. Based on our results, spring and summer 417 sampling in glacier-fed Alpine rivers should, however, not take place at high discharge in the 418 afternoon and evening and is also not advisable during floods and after strong rainfalls 419 especially without increasing the sample number or the filtered water volume (Laporte et al., 420 2020). In September and November discharge remained almost constant over time but 421 increased more than two-fold (tributary inflow) within the examined $1.3 \mathrm{~km}$. So far, most 
422 eDNA studies only discuss the effect of changing discharge (Harrison et al., 2019; Laramie, 423 Pilliod, \& Goldberg, 2015; Wood et al., 2020) even though it generally increases along the course of running waters and significantly influenced eDNA detection rates this study. Furthermore, the significance of the discharge-distance interaction term in our analysis shows the effect of the distinct hydrological conditions at each trial on eDNA detection rates 427 and signal strengths.

DNA signals and detection rates of both $P$. phoxinus and the salmonids declined significantly with increasing distance from their source, as expected from previous work on eDNA deposition and degradation (Harrison et al., 2019). At constant longitudinal and temporal discharge, average transport distance $\left(S_{P}\right)$ and depositional velocity $\left(v_{d e p}\right)$ are used

432 to describe eDNA deposition (Pont et al., 2018; Shogren et al., 2017; Wilcox et al., 2016). 433 The calculation of $v_{\text {dep }}$ relies on flow velocity and depth data, which can fluctuate considerably in natural and semi-natural rivers and are directly influenced by discharge. Therefore, we refrained from calculating this factor. $S_{P}$ is commonly described as the slope parameter of a first order exponential decline $S_{P}=1 /-k$ (but also see Wood et al., 2020). In

437 our case this would result in an average transport distance of $\sim 3,000 \mathrm{~m}$ and $\sim 850 \mathrm{~m}$ for P. phoxinus eDNA in September and November, respectively (based on data from locations with homogenous lateral eDNA distribution), and confirm the positive correlation between river size in general and transport distance (Deiner \& Altermatt, 2014; Jane et al., 2015; Pont et al., 2018; Shogren et al., 2017). However, $S_{P}$ is non-generalizable between streams

442 (Harrison et al., 2019) and thus of limited use outside of a systematic framework 443 incorporating the complex flow regime of Alpine rivers.

444 Our work aids to the understanding of how eDNA signals obtained from field-collected 445 samples can be interpreted for species monitoring and conservation. Sampling campaigns 446 carried out in dynamic habitats such as Alpine rivers and streams need to account for the 447 heterogenous lateral eDNA distribution, adapt the sampling scheme to habitat preferences of 448 the target species, and address the prevailing discharge situation. In a best-case scenario, 449 the target species has distinct habitat preferences, and discharge is low and constant during 
450 the entire sampling period. Then, eDNA quantities measured directly downstream of suitable 451 habitats are likely to be directly correlated with local target species biomass (Hinlo, 452 Lintermans, Gleeson, Broadhurst, \& Furlan, 2018). Otherwise, only discharge measurements 453 at each sampling location can prevent flawed inferences (Thalinger et al., 2019). The 454 detection of rare species, however, is best accomplished by determining a suitable distance 455 between sampling points and preliminary investigations of the respective eDNA shedding 456 rates (cp. Wood et al., 2020). The population densities and the position of individuals within 457 lotic systems should not be inferred from eDNA signals without any a priori knowledge on 458 local hydrology. Comparisons between species are also not advisable without previous tests 459 under controlled conditions. Therefore, we advocate for the reporting of the fluvial 460 morphology (e.g. pool, riffle, run), local discharge, time, and species biology during field 461 sampling. In the future, these data can be incorporated in hydrological models specifically designed for eDNA-based species monitoring.

463

464

\section{Data Availability Statement}

All data on fish, discharge, eDNA signals, environmental conditions, sampling and comparison between celPCR and APCR have been uploaded to Figshare and are available at https://doi.org/10.6084/m9.figshare.12380642.v1

469

470

\section{Acknowledgements}

472 This research was conducted within the eDNA-Alpfish project funded by the Austria 473 Research Promotion Agency (FFG); project number 853219. We thank F. Drewes for his 474 extraordinary patience, support and organisational skills during setting up the cages, fish 475 handling, and discharge measurements in the face of non-existent mobile reception. We are 476 grateful to $\mathrm{H}$. Raffl for letting us conduct the experiments in his fishing area and M. Böcker for 
477 supporting this work with her graphic skills. We thank two anonymous reviewers for their 478 constructive feedback on the original manuscript.

479

480

481 Conflict of interest

$482 \mathrm{MT}$ is the co-founder of Sinsoma $\mathrm{GmbH}$, a for-profit company dedicated to DNA analyses in 483 environmental studies; CM and RS are co-founders of the ARGE Limnologie GesmbH, a for484 profit consultancy in aquatic ecology.

485

486 Author contributions

487 MT, JW, CM, and RS conceived the study; the experiment was designed by BT, MT, RS, and 488 CM. Data were acquired and analyzed by BT, DK, and YP. BT wrote the first draft of the 489 manuscript which was revised by DK, YP, JW, and MT.

490 


\section{References}

492

493

494

495

496

497

498

499

500

501

502

503

504

505

506

507

508

509

510

511

512

513

514

515

516

517

518

519

520

521

522

523

524

525

526

527

Aarts, B. G. W., \& Nienhuis, P. H. (2003). Fish zonations and guilds as the basis for assessment of ecological integrity of large rivers. In Aquatic Biodiversity (pp. 157-178). https://doi.org/10.1007/978-94-007-1084-9_11

Akima, H., \& Gebhardt, A. (2016). akima: Interpolation of Irregularly and Regularly Spaced Data. Retrieved from https://cran.r-project.org/package=akima

Bard, A., Renard, B., Lang, M., Giuntoli, I., Korck, J., Koboltschnig, G., ... Volken, D. (2015). Trends in the hydrologic regime of Alpine rivers. Journal of Hydrology, 529, 1823-1837. https://doi.org/10.1016/j.jhydrol.2015.07.052

Barnes, M. A., \& Turner, C. R. (2016). The ecology of environmental DNA and implications for conservation genetics. Conservation Genetics, Vol. 17, pp. 1-17. https://doi.org/10.1007/s10592-015-0775-4

Bedwell, M. E., \& Goldberg, C. S. (2020). Spatial and temporal patterns of environmental DNA detection to inform sampling protocols in lentic and lotic systems. Ecology and Evolution, 10(3), 1602-1612. https://doi.org/10.1002/ece3.6014

Beng, K. C., \& Corlett, R. T. (2020). Applications of environmental DNA (eDNA) in ecology and conservation: opportunities, challenges and prospects. Biodiversity and Conservation, Vol. 29, pp. 2089-2121. https://doi.org/10.1007/s10531-020-01980-0

Bougeard, S., \& Dray, S. (2018). Supervised Multiblock Analysis in R with the ade4 Package. Journal of Statistical Software, 86(1), 1-17. https://doi.org/10.18637/jss.v086.i01

Cardinale, B. J., Duffy, J. E., Gonzalez, A., Hooper, D. U., Perrings, C., Venail, P., ... Naeem, S. (2012). Biodiversity loss and its impact on humanity. Nature, Vol. 486, pp. 59-67. https://doi.org/10.1038/nature11148

Carim, K. J., Caleb Dysthe, J., McLellan, H., Young, M. K., McKelvey, K. S., \& Schwartz, M. K. (2019). Using environmental DNA sampling to monitor the invasion of nonnative Esox lucius (northern pike) in the Columbia River basin, USA. Environmental DNA, 1(3), 215226. https://doi.org/10.1002/edn3.22

Chessel, D., Dufour, A., \& Thioulouse, J. (2004). The ade4 Package - I: One-Table Methods. R News, 4(1), 5-10. Retrieved from https://cran.r-project.org/doc/Rnews/

Clarke, A., \& Johnston, N. M. (1999). Scaling of metabolic rate with body mass and temperature in teleost fish. Journal of Animal Ecology, 68(5), 893-905. https://doi.org/10.1046/j.1365-2656.1999.00337.x

Deiner, K., \& Altermatt, F. (2014). Transport distance of invertebrate environmental DNA in a natural river. PLOS ONE, 9(2). https://doi.org/10.1371/journal.pone.0088786

Deiner, K., Bik, H. M., Mächler, E., Seymour, M., Lacoursière-Roussel, A., Altermatt, F., ... Bernatchez, L. (2017). Environmental DNA metabarcoding: Transforming how we 
528

529

530

531

532

533

534

535

536

537

538

539

540

541

542

543

544

545

546

547

548

549

550

551

552

553

554

555

556

557

558

559

560

561

562

563

564

survey animal and plant communities. Molecular Ecology, 26(21), 5872-5895. https://doi.org/10.1111/mec. 14350

Deiner, K., Fronhofer, E. A., Mächler, E., Walser, J. C., \& Altermatt, F. (2016). Environmental DNA reveals that rivers are conveyer belts of biodiversity information. Nature Communications, 7. https://doi.org/10.1038/ncomms12544

Doi, H., Inui, R., Akamatsu, Y., Kanno, K., Yamanaka, H., Takahara, T., \& Minamoto, T. (2017). Environmental DNA analysis for estimating the abundance and biomass of stream fish. Freshwater Biology, 62(1), 30-39. https://doi.org/10.1111/fwb.12846

Dowle, M., \& Srinivasan, A. (2020). data.table: Extension of 'data.frame'. Retrieved from https://cran.r-project.org/package=data.table

Evans, N. T., Shirey, P. D., Wieringa, J. G., Mahon, A. R., \& Lamberti, G. A. (2017). Comparative Cost and Effort of Fish Distribution Detection via Environmental DNA $\begin{array}{llll}\text { Analysis and } \quad \text { Electrofishing. } & \text { 90-99. }\end{array}$ https://doi.org/10.1080/03632415.2017.1276329

Faraway, J. J. (2016). Extending the Linear Model with R. Generalized Linear, Mixed Effects and Nonparametric Regression Models (2nd ed.). https://doi.org/10.1201/9781315382722

Faulks, L. K., Gilligan, D. M., \& Beheregaray, L. B. (2011). The role of anthropogenic vs. natural in-stream structures in determining connectivity and genetic diversity in an endangered freshwater fish, Macquarie perch (Macquaria australasica). Evolutionary Applications, 4(4), 589-601. https://doi.org/10.1111/j.1752-4571.2011.00183.x

Fette, M., Weber, C., Peter, A., \& Wehrli, B. (2007). Hydropower production and river rehabilitation: A case study on an alpine river. Environmental Modeling \& Assessment. Retrieved from https://doi.org/10.1007/s10666-006-9061-7

Fremier, A. K., Strickler, K. M., Parzych, J., Powers, S., \& Goldberg, C. S. (2019). Stream Transport and Retention of Environmental DNA Pulse Releases in Relation to Hydrogeomorphic Scaling Factors. Environmental Science and Technology, 53(12), 6640-6649. https://doi.org/10.1021/acs.est.8b06829

Freyhof, J., \& Kottelat, M. (2007). Handbook of European freshwater fishes . In Ichthyological Research (Vol. 55). https://doi.org/10.1007/s10228-007-0012-3

Garnier, S. (2018). viridis: Default Color Maps from "matplotlib." Retrieved from https://cran.rproject.org/package=viridis

Hagenaars, J. A., \& McCutcheon, A. L. (2002). Applied Latent Calss Analysis. In J. A. Hagenaars \& A. L. McCutcheon (Eds.), Applied Latent Class Analysis. Edinburgh: Cambridge University Press.

Harper, L. R., Buxton, A. S., Rees, H. C., Bruce, K., Brys, R., Halfmaerten, D., ... Hänfling, B. (2019). Prospects and challenges of environmental DNA (eDNA) monitoring in 
565

566

567

568

569

570

571

572

573

574

575

576

577

578

579

580

581

582

583

584

585

586

587

588

589

590

591

592

593

594

595

596

597

598

599

600

601

freshwater ponds. Hydrobiologia, Vol. 826, pp. 25-41. https://doi.org/10.1007/s10750018-3750-5

Harper, L. R., Griffiths, N. P., Lawson Handley, L., Sayer, C. D., Read, D. S., Harper, K. J., ... Hänfling, B. (2019). Development and application of environmental DNA surveillance for the threatened crucian carp ( Carassius carassius ). Freshwater Biology, 64(1), 93107. https://doi.org/10.1111/fwb.13197

Harrison, J. B., Sunday, J. M., \& Rogers, S. M. (2019). Predicting the fate of eDNA in the environment and implications for studying biodiversity. Proceedings of the Royal Society B: Biological Sciences, Vol. 286. https://doi.org/10.1098/rspb.2019.1409

Hartig, F. (2020). DHARMa: Residual Diagnostics for Hierarchical (Multi-Level / Mixed) Regression Models. Retrieved from https://cran.r-project.org/package=DHARMa

Hinlo, R., Lintermans, M., Gleeson, D., Broadhurst, B., \& Furlan, E. (2018). Performance of eDNA assays to detect and quantify an elusive benthic fish in upland streams. Biological Invasions, 20(11), 3079-3093. https://doi.org/10.1007/s10530-018-1760-x

Jane, S. F., Wilcox, T. M., Mckelvey, K. S., Young, M. K., Schwartz, M. K., Lowe, W. H., ... Whiteley, A. R. (2015). Distance, flow and PCR inhibition: EDNA dynamics in two headwater streams. Molecular Ecology Resources, 15(1), 216-227. https://doi.org/10.1111/1755-0998.12285

Jetz, W., McGeoch, M. A., Guralnick, R., Ferrier, S., Beck, J., Costello, M. J., ... Turak, E. (2019). Essential biodiversity variables for mapping and monitoring species populations. Nature Ecology and Evolution, Vol. 3, pp. 539-551. https://doi.org/10.1038/s41559-0190826-1

Kassambara, A. (2019). ggpubr: "ggplot2" Based Publication Ready Plots. Retrieved from https://cran.r-project.org/package=ggpubr

Lacoursière-Roussel, A., Rosabal, M., \& Bernatchez, L. (2016). Estimating fish abundance and biomass from eDNA concentrations: variability among capture methods and environmental conditions. Molecular Ecology Resources, 16(6), 1401-1414. https://doi.org/10.1111/1755-0998.12522

Laporte, M., Bougas, B., Côté, G., Champoux, O., Paradis, Y., Morin, J., \& Bernatchez, L. (2020). Caged fish experiment and hydrodynamic bidimensional modeling highlight the importance to consider 2D dispersion in fluvial environmental DNA studies. Environmental DNA, edn3.88. https://doi.org/10.1002/edn3.88

Laramie, M. B., Pilliod, D. S., \& Goldberg, C. S. (2015). Characterizing the distribution of an endangered salmonid using environmental DNA analysis. Biological Conservation, 183, 29-37. https://doi.org/10.1016/j.biocon.2014.11.025

Levi, T., Allen, J. M., Bell, D., Joyce, J., Russell, J. R., Tallmon, D. A., ... Yu, D. W. (2019). Environmental DNA for the enumeration and management of Pacific salmon. Molecular 
602

603

604

605

606

607

608

609

610

611

612

613

614

615

616

617

618

619

620

621

622

623

624

625

626

627

628

629

630

631

632

633

634

635

636

637

638

Ecology Resources, 19(3), 597-608. https://doi.org/10.1111/1755-0998.12987

Maruyama, A., Nakamura, K., Yamanaka, H., Kondoh, M., \& Minamoto, T. (2014). The release rate of environmental DNA from juvenile and adult fish. PLOS ONE, 9(12). https://doi.org/10.1371/journal.pone.0114639

Pont, D., Rocle, M., Valentini, A., Civade, R., Jean, P., Maire, A., ... Dejean, T. (2018). Environmental DNA reveals quantitative patterns of fish biodiversity in large rivers despite its downstream transportation. Scientific Reports, 8(1). https://doi.org/10.1038/s41598-018-28424-8

R Core Team. (2020). R: A Language and Environment for Statistical Computing. Retrieved from https://www.r-project.org/

Robinson, C. V., de Leaniz, C. G., \& Consuegra, S. (2019). Effect of artificial barriers on the distribution of the invasive signal crayfish and Chinese mitten crab. Scientific Reports, 9(1), 1-11. https://doi.org/10.1038/s41598-019-43570-3

Robinson, C. V., Uren Webster, T. M., Cable, J., James, J., \& Consuegra, S. (2018). Simultaneous detection of invasive signal crayfish, endangered white-clawed crayfish and the crayfish plague pathogen using environmental DNA. Biological Conservation, 222, 241-252. https://doi.org/10.1016/j.biocon.2018.04.009

Sales, N. G., McKenzie, M. B., Drake, J., Harper, L. R., Browett, S. S., Coscia, I., ... McDevitt, A. D. (2020). Fishing for mammals: Landscape-level monitoring of terrestrial and semi-aquatic communities using eDNA from riverine systems. Journal of Applied Ecology, 57(4), 707-716. https://doi.org/10.1111/1365-2664.13592

Sertić Perić, M., Jolidon, C., Uehlinger, U., \& Robinson, C. T. (2015). Long-term ecological patterns of alpine streams: An imprint of glacial legacies. Limnology and Oceanography, 60(3), 992-1007. https://doi.org/10.1002//no.10069

Settele, J., Scholes, R., Betts, R. A., Bunn, S., Leadley, P., Nepstad, D., ... Winter, M. (2015). Terrestrial and Inland water systems. In Climate Change 2014 Impacts, Adaptation and Vulnerability: Part A: Global and Sectoral Aspects (pp. 271-360). https://doi.org/10.1017/CBO9781107415379.009

Shogren, A. J., Tank, J. L., Andruszkiewicz, E., Olds, B., Mahon, A. R., Jerde, C. L., \& Bolster, D. (2017). Controls on eDNA movement in streams: Transport, Retention, and Resuspension /704/158/2464 /704/242 /45/77 article. Scientific Reports, 7(1). https://doi.org/10.1038/s41598-017-05223-1

Sint, D., Raso, L., \& Traugott, M. (2012). Advances in multiplex PCR: Balancing primer efficiencies and improving detection success. Methods in Ecology and Evolution, 3(5), 898-905. https://doi.org/10.1111/j.2041-210X.2012.00215.x

Takahara, T., Minamoto, T., Yamanaka, H., Doi, H., \& Kawabata, Z. (2012). Estimation of Fish Biomass Using Environmental DNA. PLOS ONE, 7(4), e35868. 
639

640

641

642

643

644

645

646

647

648

649

650

651

652

653

654

655

656

657

658

659

660

661

662

663

664

665

666

667

668

669

670

671

672

673

674

675

https://doi.org/10.1371/journal.pone.0035868

Thalinger, B., Oehm, J., Mayr, H., Obwexer, A., Zeisler, C., \& Traugott, M. (2016). Molecular prey identification in Central European piscivores. Molecular Ecology Resources, 16(1), 123-137. https://doi.org/10.1111/1755-0998.12436

Thalinger, B., Pütz, Y., \& Traugott, M. (2020). Endpoint PCR coupled with capillary electrophoresis (celPCR) provides sensitive and quantitative measures of environmental DNA in singleplex and multiplex reactions. BioRxiv, 2020.10.24.353730. https://doi.org/10.1101/2020.10.24.353730

Thalinger, B., Wolf, E., Traugott, M., \& Wanzenböck, J. (2019). Monitoring spawning migrations of potamodromous fish species via eDNA. Scientific Reports, 9(1). https://doi.org/10.1038/s41598-019-51398-0

Thomsen, P. F., \& Willerslev, E. (2015). Environmental DNA - An emerging tool in conservation for monitoring past and present biodiversity. Biological Conservation, 183, 4-18. https://doi.org/10.1016/j.biocon.2014.11.019

Tickner, D., Opperman, J. J., Abell, R., Acreman, M., Arthington, A. H., Bunn, S. E., ... Young, L. (2020). Bending the Curve of Global Freshwater Biodiversity Loss: An Emergency Recovery Plan. BioScience, 70(4), 330-342. https://doi.org/10.1093/biosci/biaa002

Tillotson, M. D., Kelly, R. P., Duda, J. J., Hoy, M., Kralj, J., \& Quinn, T. P. (2018). Concentrations of environmental DNA (eDNA) reflect spawning salmon abundance at fine spatial and temporal scales. Biological Conservation, 220, 1-11. https://doi.org/10.1016/j.biocon.2018.01.030

Vinberg, G. G. (1960). Rate of Metabolism and Food Requirements of Fishes. Nanaimo, B.C. $\square$ : Distributed by the Fisheries Research Board of Canada, Biological Station (1960).

Wacker, S., Fossøy, F., Larsen, B. M., Brandsegg, H., Sivertsgård, R., \& Karlsson, S. (2019). Downstream transport and seasonal variation in freshwater pearl mussel ( Margaritifera margaritifera ) eDNA concentration. Environmental DNA, 1(1), 64-73. https://doi.org/10.1002/edn3.10

Wickham, H. (2007). Reshaping Data with the reshape Package. Journal of Statistical Software, 21(12), 1-20. Retrieved from http://www.jstatsoft.org/v21/i12/

Wickham, H. (2016). ggplot2: Elegant Graphics for Data Analysis. Retrieved from https://ggplot2.tidyverse.org

Wilcox, T. M., McKelvey, K. S., Young, M. K., Lowe, W. H., \& Schwartz, M. K. (2015). Environmental DNA particle size distribution from Brook Trout (Salvelinus fontinalis). Conservation Genetics Resources, 7(3), 639-641. https://doi.org/10.1007/s12686-0150465-z 
676 Wilcox, T. M., McKelvey, K. S., Young, M. K., Sepulveda, A. J., Shepard, B. B., Jane, S. F.,

677 ... Schwartz, M. K. (2016). Understanding environmental DNA detection probabilities: A 678 case study using a stream-dwelling char Salvelinus fontinalis. Biological Conservation, 679 194, 209-216. https://doi.org/10.1016/j.biocon.2015.12.023

680 Willett, S. D., McCoy, S. W., Taylor Perron, J., Goren, L., \& Chen, C. Y. (2014). Dynamic 681 reorganization of River Basins. Science, 343(6175). 682 https://doi.org/10.1126/science.1248765

683 Wondzell, S. M., Gooseff, M. N., \& McGlynn, B. L. (2007). Flow velocity and the hydrologic 684 behavior of streams during baseflow. Geophysical Research Letters, 34(24), L24404. 685 https://doi.org/10.1029/2007GL031256

686 Wood, Z. T., Erdman, B. F., York, G., Trial, J. G., \& Kinnison, M. T. (2020). Experimental 687 assessment of optimal lotic eDNA sampling and assay multiplexing for a critically 688 endangered fish. Environmental DNA, edn3.64. https://doi.org/10.1002/edn3.64

689 Yates, M. C., Wilcox, T. M., McKelvey, K. S., Young, M. K., Schwartz, M. K., \& Derry, A. M. 690 (2020). Allometric scaling of eDNA production in stream-dwelling brook trout ( 691 Salvelinus fontinalis ) inferred from population size structure. Environmental DNA, 692 edn3.150. https://doi.org/10.1002/edn3.150

693 


\section{Tables and Figures}

695 Table 1: Primer pairs used for the molecular analysis of the eDNA samples. The respective target taxon, primer sequence, target gene, fragment

696 length in base pairs and the source for previously published primers are displayed. Please note that the Salvelinus sp. primer pair was designed to 697 amplify both S. fontinalis and S. umbla.

698

\begin{tabular}{|c|c|c|c|c|c|}
\hline Species & Primer name & $5^{\prime}-3^{\prime}$ & Target gene & $\begin{array}{l}\text { Fragment } \\
\text { length (bp) }\end{array}$ & Reference \\
\hline \multirow{2}{*}{ Phoxinus phoxinus } & Pho-Pho-S639 & CGTGCAGAAGCGGATATAAATAC & \multirow{2}{*}{$16 s$} & \multirow{2}{*}{128} & \multirow{2}{*}{ Thalinger et al. 2016} \\
\hline & Pho-Pho-A648 & CCAACCGAAGGTAAAGTCTTATTG & & & \\
\hline \multirow{2}{*}{ Salvelinus sp. } & Sal-vel-S651 & ATAGTCGGCACCGCCCTT & \multirow{2}{*}{$\mathrm{COI}$} & \multirow{2}{*}{112} & \multirow{2}{*}{ Thalinger et al. 2016} \\
\hline & Sal-vel-A651 & TAACGAAGGCATGGGCTGTT & & & \\
\hline Oncorhynchus mykiss & Onc-myk-A655 & GCTGGAGGTTTTATGTTAATAATGGTC & $\mathrm{COI}$ & 82 & Thalinger et al. 2016 \\
\hline \multirow{2}{*}{ Salmo trutta } & Sal-tru-S1002 & TCTCTTGATTCGGGCAGAACTC & \multirow{2}{*}{$\mathrm{COI}$} & \multirow{2}{*}{89} & \\
\hline & Sal-tru-A1002 & CGAAGGCATGGGCTGTAACA & & & \\
\hline
\end{tabular}


701 Table 2: The correlation between interpolated eDNA signals from the two fish cages. The test statistic (W) and corresponding p-values of Shapiro-

702 Wilk tests for normality are provided per trial, fish cage, and for four downstream distances (2.5 m, $5 \mathrm{~m}, 10 \mathrm{~m}$ and $20 \mathrm{~m})$. Spearman's rho and the 703 corresponding p-value were calculated per distance and trial. All displayed p-values were Holm-Sidak-corrected.

704

\begin{tabular}{|c|c|c|c|c|c|c|c|}
\hline trial & $\begin{array}{c}\text { Iongitudinal } \\
\text { position }\end{array}$ & $\begin{array}{c}\text { W } \\
\text { salmonid } \\
\text { cage }\end{array}$ & $p$-value & $\begin{array}{c}W \\
\begin{array}{c}W \\
\text { P. phoxinus } \\
\text { cage }\end{array}\end{array}$ & $\mathrm{p}$-value & Spearman's rho & $\mathrm{p}$-value \\
\hline \multirow[t]{4}{*}{ August } & $2.5 \mathrm{~m}$ & 0.89 & $<0.001$ & 0.96 & $<0.12$ & 0.89 & $<0.001$ \\
\hline & $5 \mathrm{~m}$ & 0.94 & $<0.01$ & 0.92 & $<0.001$ & 0.84 & $<0.001$ \\
\hline & $10 \mathrm{~m}$ & 0.84 & $<0.001$ & 0.93 & $<0.001$ & 0.95 & $<0.001$ \\
\hline & $20 \mathrm{~m}$ & 0.61 & $<0.001$ & 0.97 & 0.40 & 0.62 & $<0.001$ \\
\hline \multirow[t]{4}{*}{ September } & $2.5 \mathrm{~m}$ & 0.97 & 1.00 & 0.85 & $<0.001$ & 0.64 & $<0.001$ \\
\hline & $5 \mathrm{~m}$ & 0.92 & $<0.01$ & 0.87 & $<0.001$ & -0.35 & $<0.05$ \\
\hline & $10 \mathrm{~m}$ & 0.92 & $<0.01$ & 0.91 & $<0.001$ & -0.52 & $<0.001$ \\
\hline & $20 \mathrm{~m}$ & 0.87 & $<0.001$ & 0.95 & 0.21 & -0.31 & 0.08 \\
\hline \multirow[t]{4}{*}{ November } & $2.5 \mathrm{~m}$ & 0.42 & $<0.001$ & 0.96 & 1.00 & 0.30 & 1.00 \\
\hline & $5 \mathrm{~m}$ & 0.84 & $<0.01$ & 0.91 & 0.19 & -0.87 & $<0.001$ \\
\hline & $10 \mathrm{~m}$ & 0.82 & $<0.001$ & 0.76 & $<0.001$ & -0.82 & $<0.001$ \\
\hline & $20 \mathrm{~m}$ & 0.96 & 0.67 & 0.95 & 0.27 & -0.26 & 0.49 \\
\hline
\end{tabular}


707 Table 3: The difference in longitudinal eDNA signal change for the left shore, center, and right shore of the river. The change was compared 708 between the three trials per position and fish cage. The test statistic (W) and p-value of Shapiro-Wilk tests for normality are provided together with 709 the $\mathrm{Chi}^{2}$ and $\mathrm{p}$-values obtained from Kruskal-Wallis tests per position and fish-cage. The columns "September $p$-value" and "November $p$-value" 710 denote for the results of pairwise Wilcoxon-Rank-Sum tests between individual trials. All displayed p-values were Holm-Sidak-corrected.

711

\begin{tabular}{|c|c|c|c|c|c|c|c|c|c|c|}
\hline fish cage & lateral position & trial & $\begin{array}{c}\text { mean RFU- } \\
\text { change } \\
\text { per } \mathbf{m}\end{array}$ & SD & w & $p$-value & $\mathrm{Chi}^{2}$ & $p$-value & $\begin{array}{l}\text { September } \\
\text { p-value }\end{array}$ & $\begin{array}{c}\text { November } \\
p \text {-value }\end{array}$ \\
\hline \multirow[t]{9}{*}{ salmonids } & \multirow[t]{3}{*}{ left } & August & 0.0004 & 0.0013 & 0.76 & $<0.001$ & \multirow[t]{2}{*}{1043} & \multirow[t]{2}{*}{$<0.001$} & \multirow[t]{2}{*}{$<0.01$} & $<0.05$ \\
\hline & & September & 0.0034 & 0.0050 & 0.71 & $<0.001$ & & & & $<0.001$ \\
\hline & & November & 0.0078 & 0.0294 & 0.66 & $<0.001$ & & & & \\
\hline & \multirow[t]{3}{*}{ center } & August & -0.0040 & 0.0079 & 0.53 & $<0.001$ & \multirow[t]{2}{*}{1049} & \multirow[t]{2}{*}{$<0.001$} & \multirow[t]{2}{*}{$<0.001$} & $<0.001$ \\
\hline & & September & 0.0033 & 0.0130 & 0.61 & $<0.001$ & & & & $<0.001$ \\
\hline & & November & 0.0080 & 0.0133 & 0.64 & $<0.001$ & \multirow{4}{*}{954} & & & \\
\hline & \multirow[t]{3}{*}{ right } & August & -0.0011 & 0.0083 & 0.80 & $<0.001$ & & \multirow[t]{3}{*}{$<0.001$} & \multirow[t]{2}{*}{0.22} & $<0.001$ \\
\hline & & September & 0.0048 & 0.0156 & 0.77 & $<0.001$ & & & & $<0.001$ \\
\hline & & November & 0.0063 & 0.0148 & 0.68 & $<0.001$ & & & & \\
\hline \multirow[t]{9}{*}{ P. phoxinus } & \multirow[t]{3}{*}{ left } & August & 0.0033 & 0.0080 & 0.76 & $<0.001$ & \multirow[t]{3}{*}{1049} & \multirow[t]{3}{*}{$<0.001$} & \multirow[t]{3}{*}{1.00} & $<0.001$ \\
\hline & & September & 0.0076 & 0.0337 & 0.76 & $<0.001$ & & & & $<0.001$ \\
\hline & & November & -0.0300 & 0.0358 & 0.72 & $<0.001$ & & & & \\
\hline & \multirow[t]{3}{*}{ center } & August & 0.0098 & 0.0269 & 0.80 & $<0.001$ & \multirow[t]{3}{*}{1023} & \multirow[t]{3}{*}{$<0.001$} & \multirow[t]{2}{*}{$<0.001$} & $<0.001$ \\
\hline & & September & 0.0069 & 0.0234 & 0.55 & $<0.001$ & & & & $<0.001$ \\
\hline & & November & -0.0360 & 0.0549 & 0.61 & $<0.001$ & & & & \\
\hline & \multirow[t]{3}{*}{ right } & August & 0.0051 & 0.0122 & 0.83 & $<0.001$ & \multirow[t]{3}{*}{916} & \multirow[t]{3}{*}{$<0.001$} & \multirow[t]{3}{*}{$<0.05$} & $<0.001$ \\
\hline & & September & 0.0117 & 0.0130 & 0.71 & $<0.001$ & & & & $<0.001$ \\
\hline & & November & -0.0334 & 0.0538 & 0.59 & $<0.001$ & & & & \\
\hline
\end{tabular}


715 Table 4: The Generalized Linear Model (Binomial family, logit-link) describing the relation between positive detections and discharge, downstream

716 distance, their interaction, and fish species during the three cage trials. A) The columns show the test statistics ( $\mathrm{z}$-value), the lower and upper $95 \%$

717 confidence intervals, and p-values returned from the GLM for the input variables. Table B) shows the degrees of freedom (Df) residuals and

718 deviance for each variable. Note that Phoxinus phoxinus was used as base category for the description of species-specific effects.

719

\begin{tabular}{|c|c|c|c|c|c|c|}
\hline A) & Estimate & Std. Error & z-value & $\begin{array}{c}\text { lower } \\
95 \% \mathrm{Cl}\end{array}$ & $\begin{array}{c}\text { upper } \\
95 \% \mathrm{Cl}\end{array}$ & p-value \\
\hline (Intercept) & 4.64 & 0.79 & 5.91 & 3.17 & 6.26 & $<0.001$ \\
\hline discharge & -0.01 & 0.00 & -3.42 & -0.02 & 0.00 & $<0.001$ \\
\hline distance & 0.00 & 0.00 & -3.39 & -0.01 & 0.00 & $<0.001$ \\
\hline Oncorhynchus mykiss & -2.32 & 0.43 & -5.45 & -3.21 & -1.52 & $<0.001$ \\
\hline Salvelinus fontinalis & -1.86 & 0.43 & -4.37 & -2.75 & -1.06 & $<0.001$ \\
\hline Salmo trutta & -1.43 & 0.43 & -3.31 & -2.32 & -0.61 & $<0.001$ \\
\hline discharge $e^{\star}$ distance & 0.00 & 0.00 & 3.32 & 0.00 & 0.00 & $<0.001$ \\
\hline B) & Df & Deviance & & Resid. Df & Resid. Dev & \\
\hline NULL & & & & 335 & 431.78 & \\
\hline discharge & 1 & 3.728 & & 334 & 428.05 & \\
\hline distance & 1 & 0.433 & & 333 & 427.62 & \\
\hline fish species & 3 & 39.212 & & 330 & 388.4 & \\
\hline discharge $^{*}$ distance & 1 & 12.017 & & 329 & 376.39 & \\
\hline
\end{tabular}


Table 5: The Generalized Linear Model (Gamma-family, log-link) describing the relation between RFU and discharge, downstream distance, their

\begin{tabular}{lcccccr} 
A) & Estimate & Std. Error & t-value & $\begin{array}{c}\text { lower } \\
\mathbf{9 5 \%} \mathbf{~ C l}\end{array}$ & $\begin{array}{c}\text { upper } \\
\mathbf{9 5 \%} \mathbf{~ C l}\end{array}$ & $\mathbf{p}$-value \\
\hline (Intercept) & -0.42 & 0.22 & -1.96 & -0.82 & -0.01 & 0.05 \\
discharge & 0.00 & 0.00 & -1.74 & 0.00 & 0.00 & 0.08 \\
distance & 0.00 & 0.00 & -4.21 & 0.00 & 0.00 & $<0.001$ \\
Oncorhynchus mykiss & -0.33 & 0.13 & -2.52 & -0.58 & -0.07 & $<0.05$ \\
Salvelinus fontinalis & -0.38 & 0.12 & -3.14 & -0.62 & -0.14 & $<0.01$ \\
Salmo trutta & -0.30 & 0.12 & -2.61 & -0.53 & -0.07 & $<0.01$ \\
discharge*distance & 0.00 & 0.00 & 3.25 & 0.00 & 0.00 & $<0.01$ \\
\hline
\end{tabular}

727

\begin{tabular}{lcccc} 
B) & Df & Deviance & Resid. Df & Resid. Dev \\
\hline NULL & & & 220 & 125.14 \\
discharge & 1 & 1.4257 & 219 & 123.72 \\
distance & 1 & 3.8624 & 218 & 119.85 \\
fish species & 3 & 4.9894 & 215 & 114.86 \\
discharge*distance & 1 & 5.0312 & 214 & 109.83 \\
\hline
\end{tabular}


729 Figure 1: The geographic location of the study region and the aerial view (source: Land Tirol -

730 data.gv.at) of the sampling reach is displayed with yellow dots showing the individual sampling

731 locations at $1.3 \mathrm{~km}, 555 \mathrm{~m}, 425 \mathrm{~m}, 325 \mathrm{~m}, 225 \mathrm{~m}, 130 \mathrm{~m}, 65 \mathrm{~m}, 33 \mathrm{~m}, 17 \mathrm{~m}, 8 \mathrm{~m}, 4 \mathrm{~m}, 2.5 \mathrm{~m}$

732 and $0.5 \mathrm{~m}$. Note that downstream distances between $0.5 \mathrm{~m}$ and $17 \mathrm{~m}$ are not fully resolved in

733 the aerial view. The illustrations show the cage placement in the stream, individual transect

734 samples, and the hydrological conditions prevailing during the August, September, and

735 November trials. Larger flowlines and eddies code for stronger currents. Due to reduced

736 discharge, the relative location and number of eDNA samples were not kept uniform between

737 trials.

738

739 Figure 2: Heatmaps showing the small-scale $(\leq 20 \mathrm{~m})$ distribution of eDNA downstream of the 740 salmonid cage (upper panel) and Phoxinus phoxinus cage (lower panel) during August,

741 September, and November. The arrow indicates the flow direction and the cages were placed at 742 zero on the y-axis. As eDNA signals differed between the salmonids and $P$. phoxinus, different 743 colour scales where used between these two groups. Isotherms display interpolated differences

744 of 0.05 RFU. Dashed lines to the left and the bottom of the figures show locations of lateral and 745 longitudinal transects used to compute small-scale differences in eDNA signals; these transects 746 differ from the actual water sampling locations. Note, that the irregular shape in November 747 reflects a gradual increase in wetted width downstream of the cages.

749 Figure 3: eDNA signal strength of Phoxinus phoxinus and salmonids (upper panel) as well as

750 the corresponding discharge (lower panel) determined at different distances from the cages in 751 August, September, and November. The eDNA signal strength was measured in Relative 752 Fluorescence Units (RFU) and is displayed for downstream distances with homogeneous lateral 753 eDNA distribution ( $\geq 130 \mathrm{~m}$ ). Samples testing negative were not considered for this illustration. 
755 Figure 4: Overall eDNA signal strength measured in Relative Fluorescence Units (RFU) 756 considering water samples collected at distances $\geq 130 \mathrm{~m}$ in August, September, and November.

757 The RFU of positive samples are displayed as boxplots for each fish species individually; the

758 empty circles code for the mean RFU. Underneath each boxplot, the number of samples testing

759 positive / the total sample number are displayed. The pie charts show the proportion of PCR

760 positives for P. phoxinus ("Pho pho") and the three salmonid species ("Onc myk" =

761 Oncorhynchus mykiss, "Sal fon" = Salvelinus fontinalis, "Sal tru" = Salmo trutta) per trial with

762 dark shading coding for successful detection. 

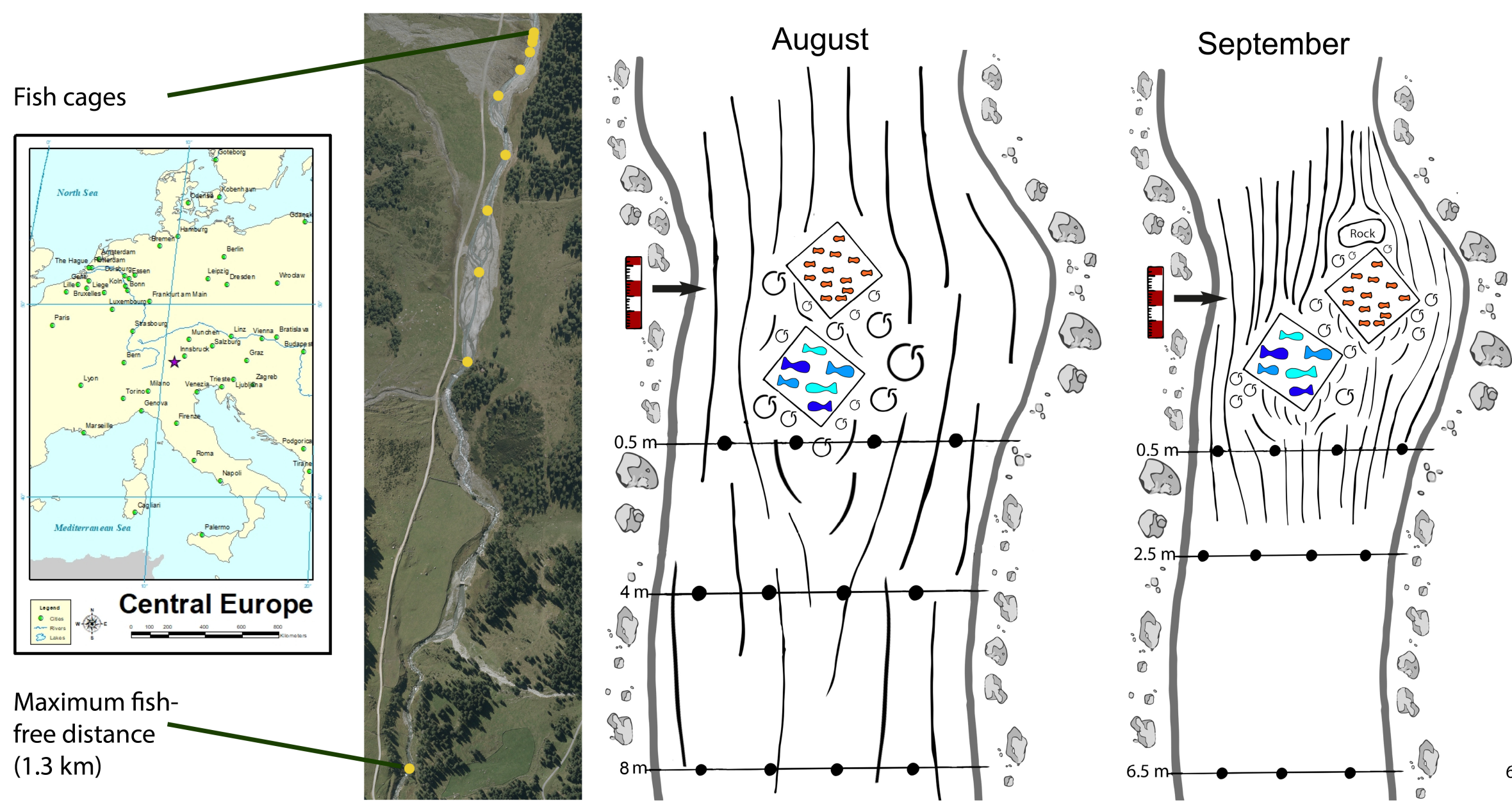

November

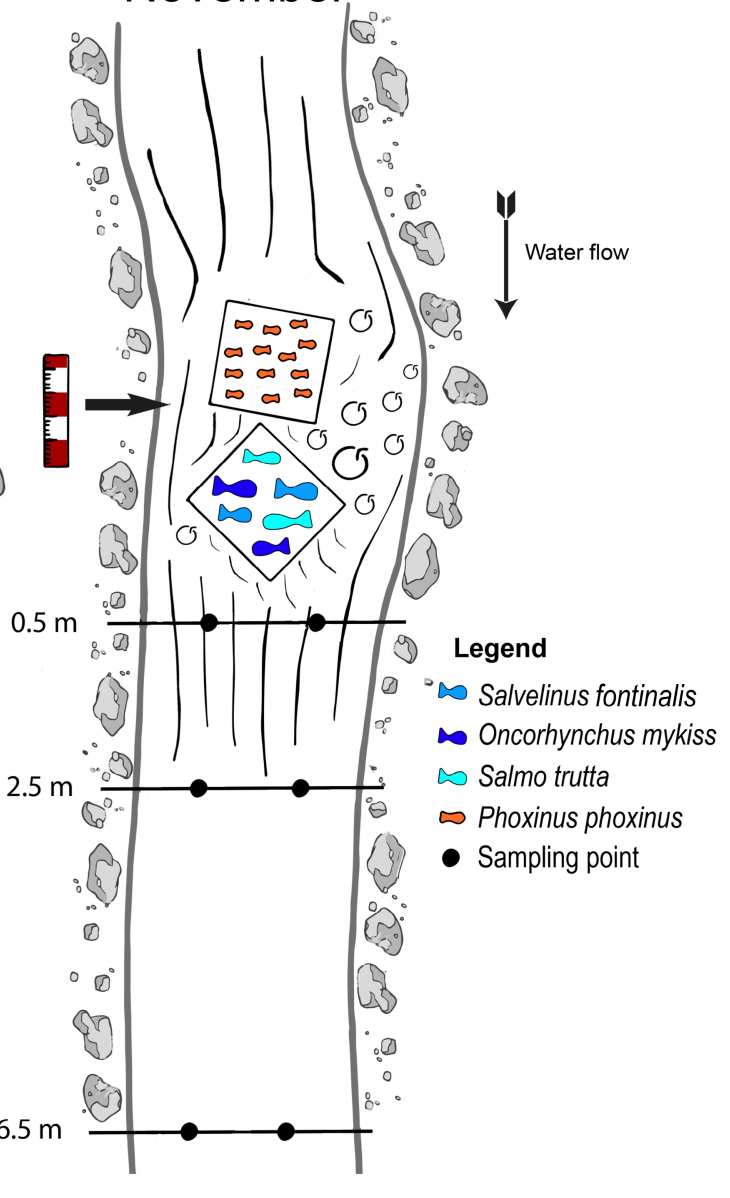



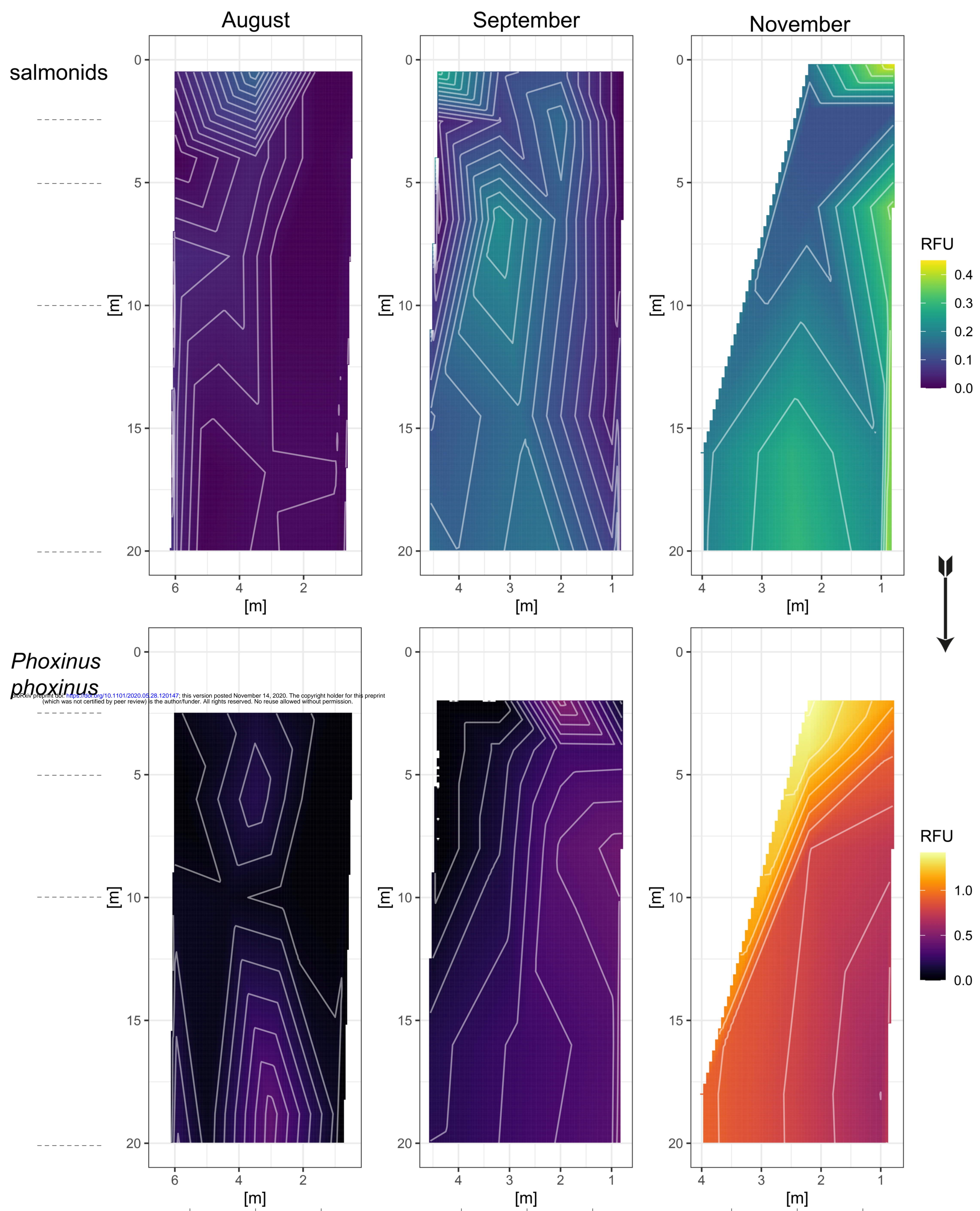
August

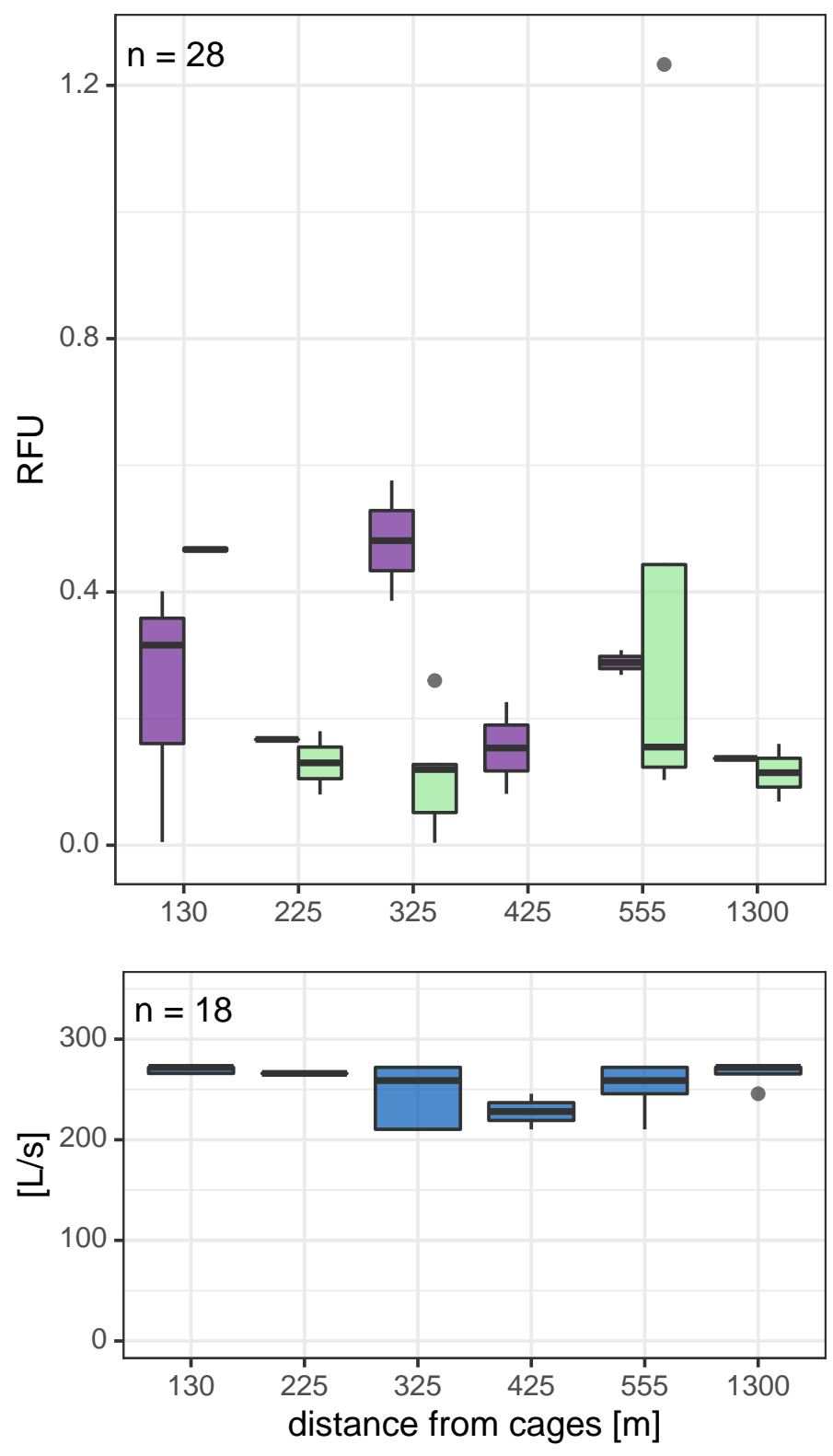

\section{September}
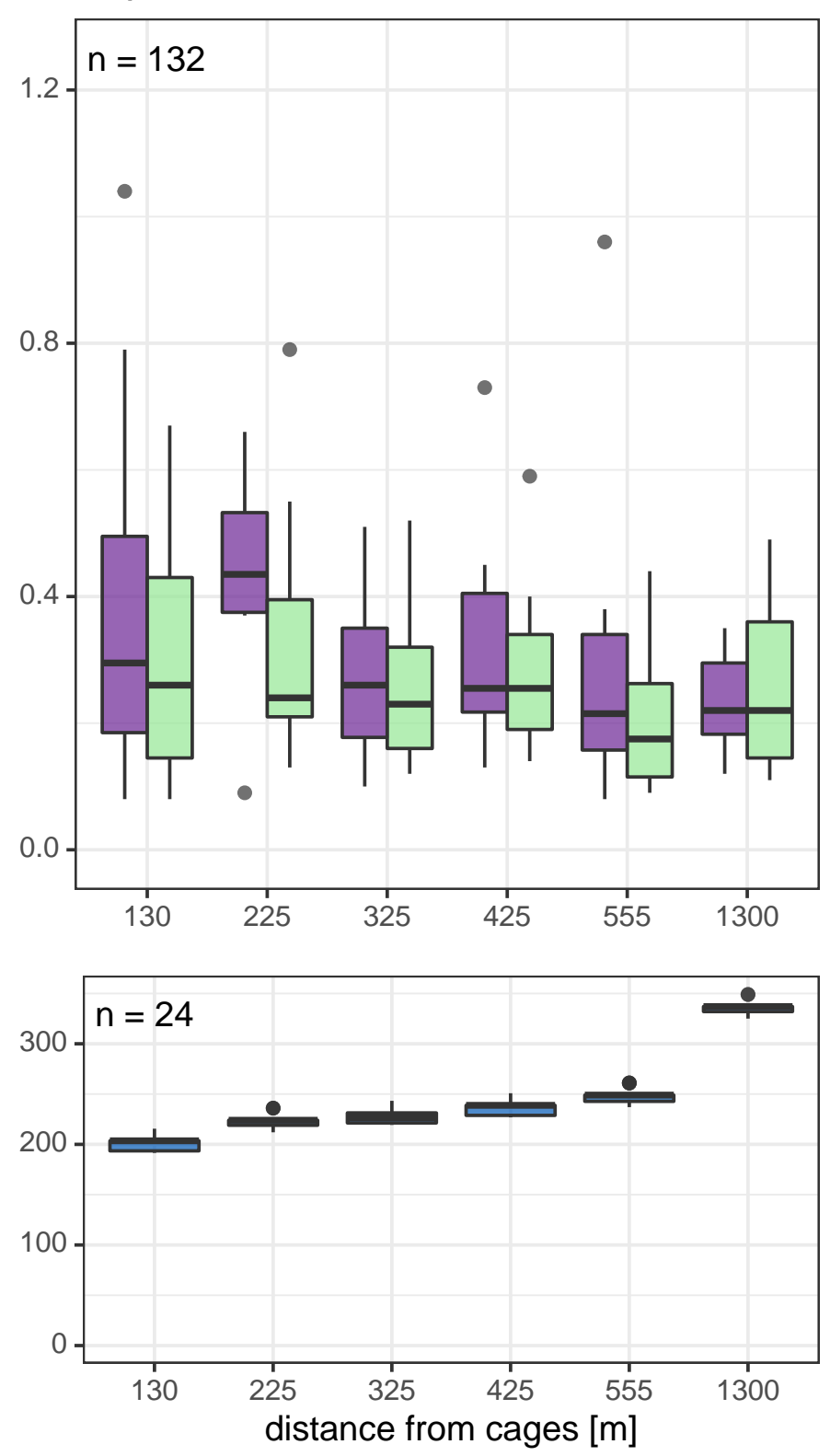

P.phoxinus salmonids

\section{November}
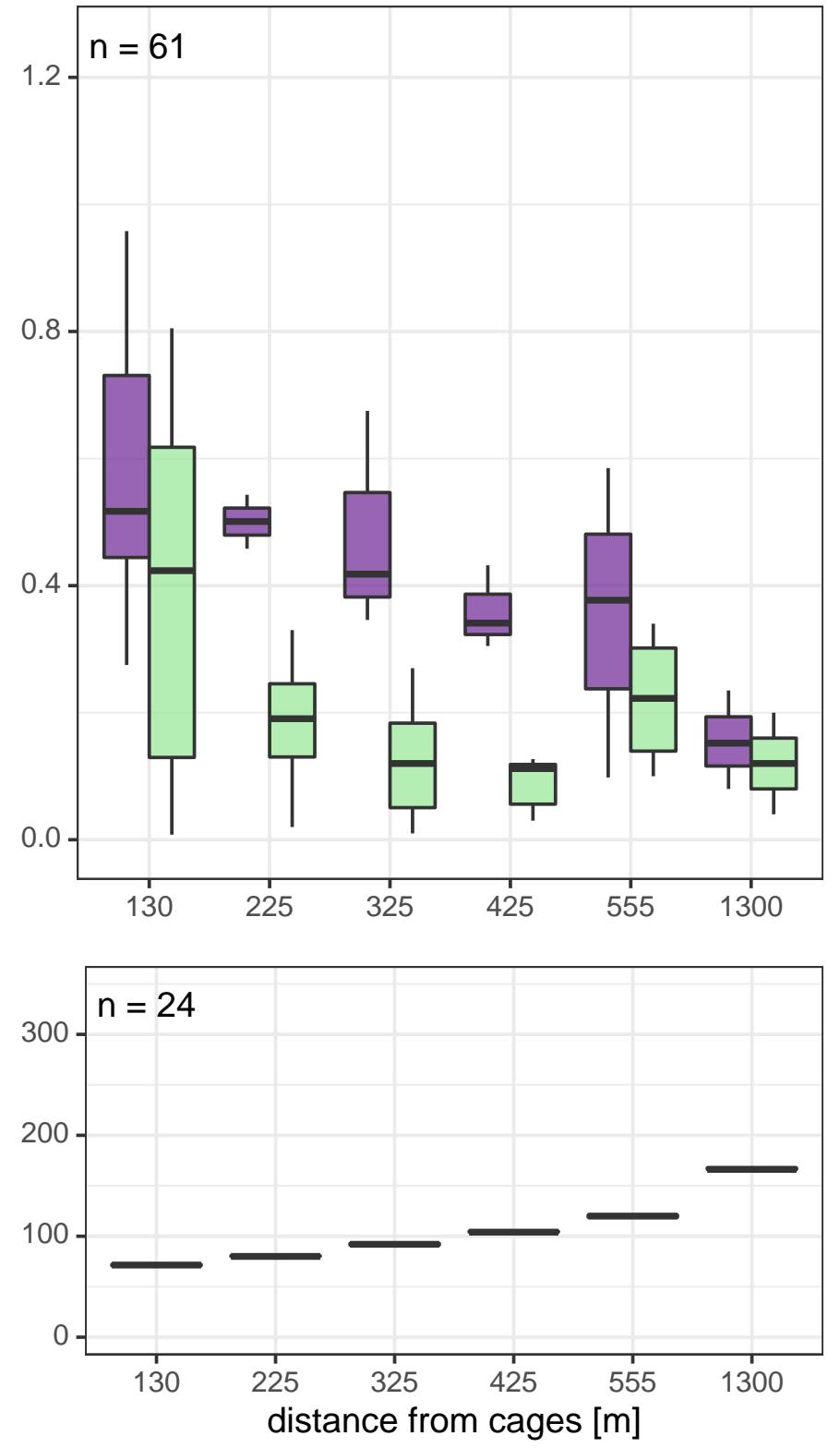


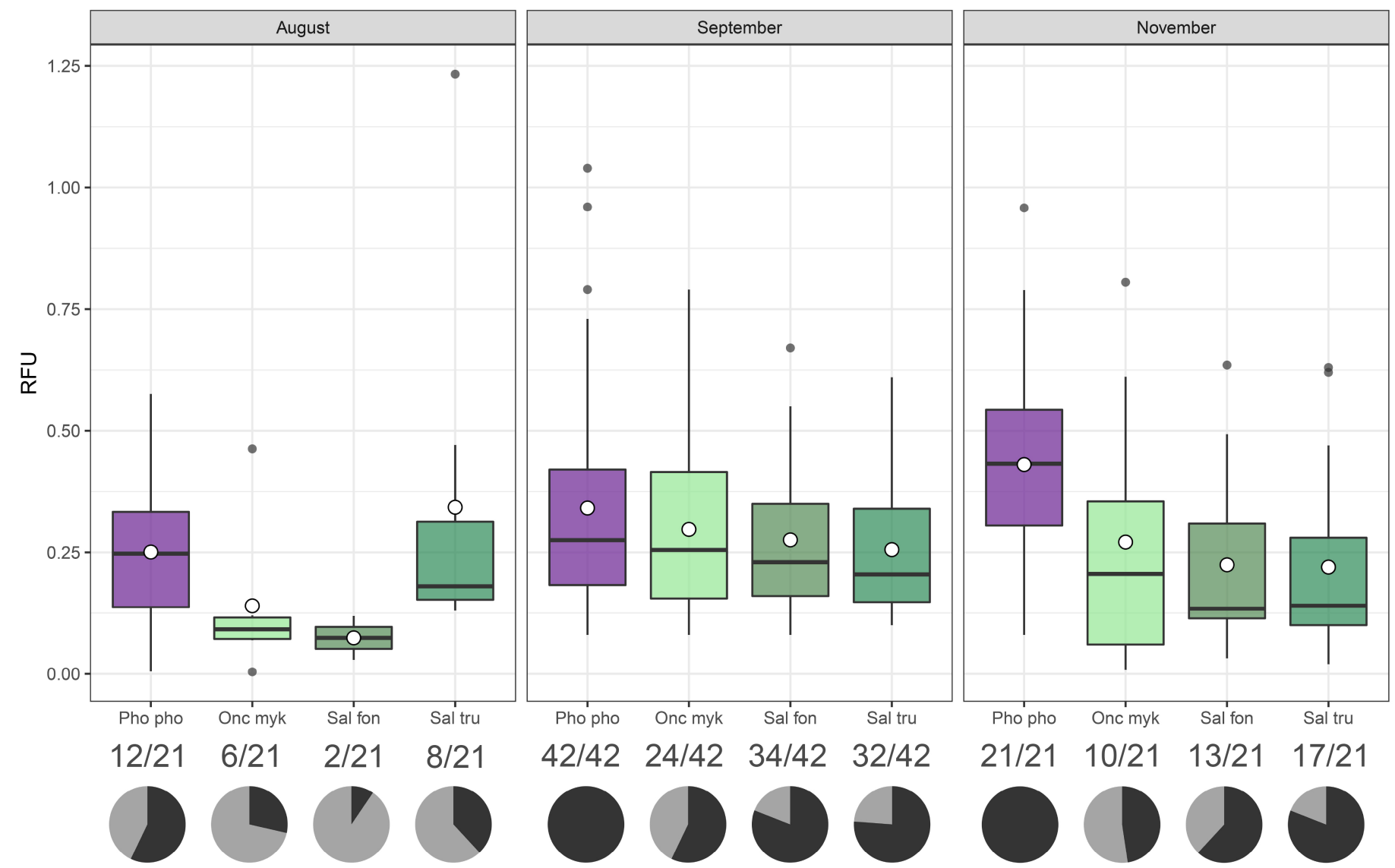

